FRBSF Working Paper \#2003-02

\title{
Human Capital and Technology Diffusion*
}

\author{
Jess Benhabib and Mark M. Spiegel ${ }^{\dagger}$
}

December 9, 2002

\begin{abstract}
This paper generalizes the Nelson-Phelps catch-up model of technology diffusion. We allow for the possibility that the pattern of technology difusion can be exponential, which would predict that nations would exhibit positive catch-up with the leader nation, or logistic, in which a country with a sufficiently small capital stock may exhibit slower total factor productivity growth than the leader nation.

We derive a nonlinear specification for total factor productivity growth that nests these two specifications. We estimate this specification for a cross-section of nations from 1960 through 1995. Our results support the logistic specification, and are robust to a number of sensitivity checks.

Our model also appears to predict slow total factor productivity growth well. 22 of the 27 nations that we identify as lacking the critical human capital levels needed to achieve faster total factor productivity growth than the leader nation in 1960 did achieve lower growth over the next 35 years.
\end{abstract}

\section{J.E.L. Classification Number: O4}

Keywords: human capital, technology diffusion

*Send correspondence to Mark M. Spiegel, Economic Research, Federal Reserve Bank of San Francisco, 101 Market St., San Francisco, CA, 94105, mark.spiegel@sf.frb.org, (415)-974-3241.

$\dagger^{\dagger}$ New York University and Federal Reserve Bank of San Francisco. Very helpful comments were received from Richard Dennis, Rody Manuelli, Chris Papageorgiou, and seminar participants at LSU, USC, and the SIEPR/FRBSF Conference on Technical Change. Edmund Chiang provided excellent research assistance. The opinions in this paper are the author's own, and do not necessarily reflect those of the Federal Reserve Bank of San Francisco, or the Board of Governors of the Federal Reserve. We thank the C. V. Starr Center at NYU for technical assistance. 


\section{Introduction}

In a short paper in 1966 Nelson and Phelps offered a new hypothesis to explain economic growth. Their explanation had two distinct components. The first component postulated that while the growth of the technology frontier reflects the rate at which new discoveries are made, the growth of total factor productivity depends on the implementation of these discoveries, and varies positively with the distance between the technology frontier and the level of current productivity. Applied to the diffusion of technology between countries, with the country leading in total factor productivity representing the technology frontier, this is a formalization of the catch-up hypothesis that was originally proposed by Gerschenkron (1962). The second component of the Nelson-Phelps hypothesis suggested that the rate at which the gap between the technology frontier and the current level of productivity is closed depends on the level of human capital. This was a break with the view that human capital is an input into the production process. Nelson and Phelps make this point starkly in the concluding sentence of their paper: "Our view suggests that the usual, straightforward insertion of some index of educational attainment in the production function may constitute a gross mis-specification of the relation between education and the dynamics of production."

The catch-up or technology diffusion component of the Nelson-Phelps hypothesis raises a basic question. If a country, or a firm within an industry, has to incur costs in order to innovate, then why should it not sit back and wait for technology diffusion that flows costlessly? Modern theories of economic growth have paid a great deal of attention to the incentives for innovation and to the market structures that are necessary to sustain $\mathrm{R} \& \mathrm{D}$. Inventions are typically assumed to give rise to new (often intermediate) products which generate monopoly rents over their lifetime. These rents provide the financial incentives to innovate and to cover the costs of innovation. The costs of invention typically reflect the wages or the patent incomes of researchers. The labor markets allocate workers between 
research and production, and in certain cases the allocation of workers across different occupations can involve decisions to acquire costly human capital. When a vintage structure is present, newer and technologically more efficient intermediate goods or production processes may coexist with older ones that remain inside the technology frontier. A critical by-product of an innovation, not captured by the monopoly rents that it generates, is the expansion of the stock of basic knowledge This basic knowledge, freely available to all, enhances the productivity of future research, facilitates future innovations and is the source of scale effects.

In the Nelson-Phelps framework, disembodied technical know-how flows from the technology leader to its followers and augments their total factor productivity. Patent protection or blueprint ownership is not explicitly postulated, and therefore an alternative mechanism must be in operation to sustain inventive activity and to prevent free-riding. A number of models have directly addressed the impact of imitation that dissipates rents on innovative activity by explicitly introducing costs of imitation. In an early investigation by Grossman and Helpman (1991, Chapter 11, see also Helpman (1993), Segerstrom (1991)), the North, where patent protection is in effect, innovates, and the South, where labor costs are lower, imitates at a cost. Aghion, Harris and Vickers (1997), building on Grossman and Helpman (1991), suggest a leapfrogging model where firms can, by incurring an appropriate cost, catch-up and overtake their rivals to capture a larger share of the profits. To construct an equilibrium with technology diffusion, Barro and Sala-i Martin [1995, also (1997)] introduce a model where in the leading country the costs of innovation are low relative to the costs of imitation, while in the follower country the reverse is true. Basu and Weil (1998) propose a model where technological barriers to imitation in the South arise from significant differences in factor proportions between North and South, with the possible emergence of "convergence clubs" Such differences in endowments may not provide the most "appropriate" opportunities for imitation, and fail to direct 
technical change towards efficient cost savings (see Acemoglu (2002)). Technology may nevertheless flow between convergence clubs, with imitation costs rather than patent protection sustaining innovative activity within the clubs. Eeckhout and Jovanovic (2002) construct a model where imitators can implement technology only with a lag, and this implicit imitation cost means that innovators find it optimal to maintain their lead. It seems clear then that some costs of imitation and certain advantages to innovation must be present if technology diffusion is to play a role in economic growth. Underlying the Nelson-Phelps model therefore, there must be an appropriate market structure and an economic equilibrium that sustains innovative activity in the face of technology diffusion.

The empirical literature on technology diffusion has been growing, despite difficulties in measurements. The survey of Griliches (1992) lends support to the view that there are significant R\&D spillovers. Coe and Helpman (1995) find that R\&D abroad benefits domestic productivity, possibly through the transfer of technological know-how via trade. Branstetter (1996), looking at disaggregated data, finds research spillovers across firms that are close in "technology space." Nadiri and Kim (1996) suggest that the importance of research spillovers across countries varies with the country: domestic research seems important in explaining productivity in the US but the contribution of foreign research is more important for countries like Italy or Canada. The role of human capital in facilitating technology adoption is documented by Welch (1975), Bartel and Lichtenberg (1987) and Foster and Rosenzweig (1995). Benhabib and Spiegel (1994), using cross-country data, investigate the Nelson-Phelps hypothesis and conclude that technology spillovers flow from leaders to followers, and that the rate of the flow depends on levels of education. In fact a good deal of the recent empirical literature has focused on whether the level of education speeds technology diffusion and leads to growth, as suggested by Nelson Phelps, or whether education acts as a factor of production, either directly or through facilitating technology use. (See 
for example, Islam (1995), Temple (1999), Krueger and Lindahl (2001), Pritchett, Klenow and Rodriguez-Clare (1997), Hall and Jones (1999), Bils and Klenow (2000), Duffy and Papageorgiou (2000), and Hanushek and Kimko (2000)).

The policy implications of distinguishing between the role of education as a factor of production and a factor that facilitates technology diffusion are significant. In the former, the benefit of an increase in education is its marginal product. In the latter, because the level of education affects the growth rate of total factor productivity and output, its benefit will be measured in terms of the sum of its impact on all output levels in the future. Following Nelson and Phelps (1966), in Benhabib and Spiegel (1994) we characterize the latter relationship through a specification to explain growth that includes a term interacting the stock of human capital with backwardness, measured as a country's distance from the technology leader.

There are potentially important implications of distinguishing between different functional forms for the technology diffusion process. The technology diffusion process specified by Nelson and Phelps and widely used in the literature is known as the confined exponential diffusion [Banks (1994)]. An alternative diffusion process is the logistic model of technology diffusion. A priori, there appears to be no reason to favor one of these technology diffusion specifications over the other, and the two specifications differ by very little. Nevertheless, as we demonstrate below, these specifications can have very different implications for a nation's growth path: For the exponential diffusion process, the steady state is, for all parametrization, a balanced growth path, with all followers growing at the pace determined by the leader nation that acts as the locomotive. In contrast, the logistic model allows for a dampening of the diffusion process so that the gap between the leader and a follower can keep growing. Indeed, we demonstrate that if the human capital stock of a follower is sufficiently low, the logistic diffusion model does not imply catch-up, but a divergence in total factor productivity 
growth rates. On this point, also see Howitt and Mayer-Foulkes (2002).

Below we derive an empirical specification that nests these two forms of technology diffusion in a model where total factor productivity growth depends on initial backwardness relative to the stock of potential world knowledge, proxied in our model as the total factor productivity level of the leader country. We then test this specification for a cross-section of total factor productivity growth of 84 countries from 1960 through 1995. We obtain robust results supporting a positive role for human capital as an engine of innovation, as well as a facilitator of catch-up in total factor productivity.

Since our empirical results favor a logistic form of technology diffusion, some countries may indeed experience divergence in total factor productivity growth. To investigate our results, we derive a point estimate from our estimation results for the minimum initial human capital level necessary to exhibit catch-up in total factor productivity relative to the leader nation, which, in our sample, is the United States. The point estimate in our favored specification indicates that an average of 1.78 years of schooling was required in 1960 to achieve convergence in total factor productivity growth with the United States.

Under this criterion, we identify 27 countries in our sample that our point estimates predict will exhibit slower total factor productivity growth than the United States. Our data shows that over the next 35 years, 22 of these 27 countries did indeed fall farther behind the United States in total factor productivity, while the remaining bulk of the nations in our sample exhibited positive catch-up in total factor productivity. While this result is not a formal test of our model, its ability to correctly identify countries that would subsequently exhibit slower total factor productivity growth than the United States is reassuring.

We then repeat our exercise using 1995 figures to identify the set of nations that are still falling behind in total factor productivity growth. Because the United States had higher education levels in 1995, we estimate a higher threshold 
level for total factor productivity growth convergence with the United States. Our estimate was that 1.95 average years of schooling in the population over the age of 25 was necessary for faster total factor productivity growth than the leader nation. Fortunately, the higher overall education levels achieved by most countries over the past 35 years left few countries falling the threshold levels in education to achieve catch-up in growth rates. We identified only four countries as still below the threshold in 1995: Mali, Mozambique, Nepal, and Niger. With the exception of these four nations, our results indicate that most of the world is not in a permanent development trap, at least in terms of total factor productivity growth. Nevertheless, it should be pointed out that catch-up in total factor productivity is not a guarantee of convergence in per capita income, as nations must also be successful in attracting physical capital to achieve the latter goal.

The remainder of the paper is divided into five sections. Section 2 introduces the exponential and logistic specifications of the Nelson-Phelps model and examines their steady-state implications. Section 3 compares the diffusion models with that of Barro and Sala-i-Martin (1997). Section 4 derives a non-linear growth specification that nests the exponential and logistic technology diffusion functional forms. Section 5 estimates this model using maximum likelihood for a cross-section of countries. Section 6 uses the point estimates from our estimation to identify nations that are predicted to fail to exhibit divergence in total factor productivity growth in 1960 and 1995. Lastly, Section 7 concludes.

\section{Variations on the Nelson-Phelps Model}

We will examine the implications of two types processes often studied in the context of disaggregated models of technology diffusion [Banks (1994)]. We can express the original Nelson-Phelps model of technology diffusion as follows:

$$
\frac{\dot{A}_{i}(t)}{A_{i}(t)}=g\left(H_{i}(t)\right)+c\left(H_{i}(t)\right)\left(\frac{A_{m}(t)}{A_{i}(t)}-1\right)
$$


where $A_{i}(t)$ is the TFP, $g_{i}\left(H_{i}(t)\right)$ is the component of TFP growth that depends on the level of education $H_{i}(t)$ in country $i$ and $c\left(H_{i}(t)\right)\left(\frac{A_{m}(t)}{A_{i}(t)}-1\right)$ represents the rate of technology diffusion from the leader country $m$ to country $i$. We assume that $c_{i}(\cdot)$ and $g_{i}(\cdot)$ are increasing functions. The level of education $H_{i}(t)$ affects the rate at which the technology gap $\left(\frac{A_{m}(t)}{A_{i}(t)}-1\right)$ is closed. If the ranking of $g_{i}\left(H_{i}(t)\right)$ across countries do not change, or if $H_{i}^{\prime} s$ are constant, a technology leader will emerge in finite time with $g_{m}=g\left(H_{m}(t)\right)>g\left(H_{i}(t)\right)=g_{i}$. After that the leader will grow at rate $g_{m}$ and the followers will fall behind in levels of TFP until the point at which their growth rate will match the leader's growth rate $g_{m}$ This can be seen from the solution of the above equation when $H_{i}$ 's are constant 1 :

$$
A_{i}(t)=\left(A_{i}(0)-\Omega A_{m}(0)\right) e^{\left(g_{i}-c_{i}\right) t}+\Omega A_{m}(0) e^{g_{m} t}
$$

where $c_{i}=c\left(H_{i}\right), g_{i}=g\left(H_{i}\right)$ and

$$
\Omega=\frac{c_{i}}{c_{i}-g_{i}+g_{m}}>0 .
$$

It is clear, since $g_{m}>g_{i}$, that

$$
\lim _{t \rightarrow \infty} \frac{A_{i}(t)}{A_{m}(t)}=\Omega
$$

This is, for all parametrizations, a world balanced growth path with the leader acting as the "locomotive." Technology diffusion and "catch-up" assures that despite scale effects and educational differences, all countries eventually grow at the same rate. ${ }^{2}$

$$
\begin{aligned}
& { }^{1} \text { The general solution when } H_{i} \text { 's are not constant is given by: } \\
& \begin{aligned}
A_{i}(t)=A_{i}(0) e^{-\int_{0}^{t}\left(g\left(H_{i}(s)\right)-c\left(H_{i}(s)\right)\right) d s} \\
\cdot\left[1+\frac{1}{A_{i}(0)}\left(\int_{0}^{t} c\left(H_{i}(\tau)\right)\left(A_{m}(0) e^{\int_{0}^{\tau} g\left(H_{m}(\zeta)\right) d \zeta}\right) e^{\int_{0}^{\tau}\left(g\left(H_{i}(\xi)\right)-c\left(H_{i}(\xi)\right)\right) d \xi} d \tau\right)\right]
\end{aligned}
\end{aligned}
$$

${ }^{2}$ Note however that in transition, the higher is initial $A_{i}(0)$, the smaller is the technology gap to the leader and therefore the slower is the growth. This negative dependence on initial 
The technology diffusion and catch-up processes outlined above are also known as the confined exponential diffusion process (see Banks(1994)) An alternative formulation that is similar in spirit is the logistic model of technology diffusion (see Sharif and Ramanthran (1981)). It is given by

$$
\begin{aligned}
\frac{\dot{A}_{i}(t)}{A_{i}(t)} & =g\left(H_{i}(t)\right)+c\left(H_{i}(t)\right)\left(1-\frac{A_{i}(t)}{A_{m}(t)}\right) \\
& =g\left(H_{i}(t)\right)+c\left(H_{i}(t)\right)\left(\frac{A_{i}(t)}{A_{m}(t)}\right)\left(\frac{A_{m}(t)}{A_{i}(t)}-1\right)
\end{aligned}
$$

The difference of the dynamics under the logistic model of technology diffusion and the confined exponential one is due to the presence of the extra term $\left(\frac{A_{i}(t)}{A_{m}(t)}\right)$. This term acts to dampen the rate rate of diffusion as the distance to the leader increases, reflecting perhaps the difficulty of adopting distant technologies. As shown by Basu and Weil (1998), the frontier technology may not be immediately "appropriate" for the follower if differences in factor proportions between leader and follower are large. We may observe convergence clubs, as documented by Durlauf and Johnson (1995), from which follower countries can break out only by investing in physical and human capital. Catch-up therefore may be slower when the leader is either too distant or too close, and is fastest at intermediate distances. ${ }^{3}$

If we assume, as before, that $H_{i}$ 's (and therefore, $c_{i}$ 's and $g_{i}$ 's) are constant

conditions is similar to standard convergence results in the neoclassical growth model, but the logic of catch-up is different.

${ }^{3}$ An alternative view of technology adoption through diffusion that follows a logitic pattern borrows from epidemiology. The rate of adoption in a fixed population may depend on the rate of contact between adopters and hold-outs (those that are infected and those that are healthy). The adoption rate is highest when there are an equal number of both types, and lower when there is either a small or a large proportion of adopters. Also observing the successes and implementation errors of the first adopters, together with the competitive pressures that first adopters create, may result in a speeding up of adoption rates. See Mansfield (1968). 
such that $H_{m}>H_{i}$, and therefore that $c\left(H_{m}\right)>c\left(H_{i}\right)$, then the solution to the logistic technology diffusion equation is given by 456

$$
A_{i}(t)=\frac{A_{i}(0) e^{\left(g_{i}+c_{i}\right) t}}{\left(1+\frac{A_{i}(0)}{A_{m}(0)} \frac{c_{i}}{\left(c_{i}+g_{i}-g_{m}\right)}\left(e^{\left(c_{i}+g_{i}-g_{m}\right) t}-1\right)\right)}>0
$$

This equation can be written as

$$
A_{i}(t)=\frac{A_{m}(0) e^{g_{m} t}}{\left(e^{-\left(c_{i}+g_{i}-g_{m}\right) t}\left(\frac{A_{m}(0)}{A_{i}(0)}-\frac{c_{i}}{\left(c_{i}+g_{i}-g_{m}\right)}\right)+\frac{c_{i}}{\left(c_{i}+g_{i}-g_{m}\right)}\right)}
$$

so that in the limit,

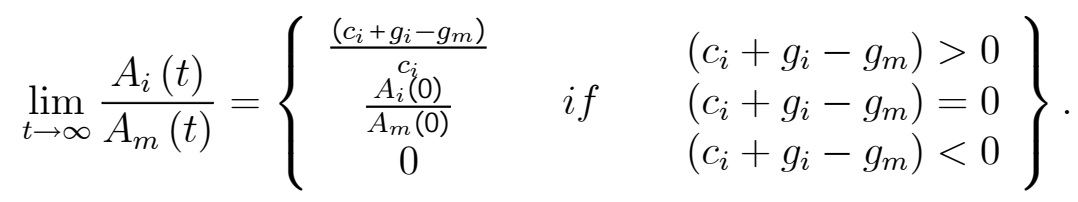

Equation (2.6) implies that in the case of the logistic diffusion model, the steady state growth relationship will depend on the relative magnitude of the catch-up rate and the difference in the growth rate due to innovation, $g_{m}-g_{i}$. If the catch-up rate exceeds the differential growth rate solely due to educational differences between the leader and follower, that is if $c\left(H_{i}\right)+g\left(H_{i}\right)-g\left(H_{m}\right)>0$, then the leader will have a locomotive effect and pull the followers along. In such a case growth rates will converge. However, if the education level of a follower is

\footnotetext{
${ }^{4}$ Provided that $\left(c_{i}+g_{i}-g_{m}\right) \neq 0$. If $\left(c_{i}+g_{i}-g_{m}\right)=0$, then the equation reduces to exponential form $A_{i}(t)=A_{i}(0) e^{\left(g_{i}+c_{i}\right) t}$.

${ }^{5}$ The general solution where $H_{i}$ 's are functions of time can be computed by defining $B_{i}=\left(A_{i}\right)^{-1}$ and transforming the logistic form into the confined exponential. After some computations, the general form can be obtained as

$$
\begin{aligned}
& A_{i}(t)=\frac{A_{i}(0) e^{\int_{0}^{t}\left(g\left(H_{i}(s)\right)+c\left(H_{i}(s)\right)\right) d s}}{\left(1+A_{i}(0)\left(\int_{0}^{t} c\left(H_{i}(\tau)\right)\left(\left(A_{m}(0)^{-1}\right) e^{-\int_{0}^{\tau} g\left(H_{m}(\zeta)\right) d \zeta}\right) e^{\int_{0}^{\tau}\left(g\left(H_{i}(\xi)\right)+c\left(H_{i}(\xi)\right)\right) d \xi} d \tau\right)\right)} \\
& { }^{6} A_{i}(t)>0 \text { because when } c_{i}+g_{i}-g_{m} \neq 0, \frac{c_{i}}{\left(c_{i}+g_{i}-g_{m}\right)}\left(e^{\left(c_{i}+g_{i}-g_{m}\right) t}-1\right)>0 .
\end{aligned}
$$
}


so low that $c\left(H_{i}\right)+g\left(H_{i}\right)-g\left(H_{m}\right)<0$, then the follower will not be able to keep up, growth rates will diverge, and the income ratio of the follower to the leader will go to zero.

This highlights the critical role of the type of technology diffusion process and its interaction with education in fostering economic growth: a country with a low level of education may still keep within the gravitational pull of the technology leader, provided that the level of education is high enough to permit sufficient diffusion. If technology diffusion is of the logistic type, countries with educational levels that are too low will get left behind and we may observe the phenomenon of "convergence clubs." Escaping from the lower "club" is nevertheless possible through investments in human capital, as discussed by Basu and Weil (1998) ${ }^{7}$. The implications of logistic versus exponential technology diffusion for economic growth can therefore be quite divergent.

Note that we can append the Nelson-Phelps framework, either in the logistic or the confined exponential form, to the Romer (1990) model by adding the catchup term the research sector producing the blueprints $A$. The marginal product of $H$ in the research sector will now reflect an effect from the catch-up term, and increase the allocation of $H$ towards the research sector away from production or leisure. If, as in Romer, we assume that $H$ is constant while knowledge, $A$, is accumulated, and also assume that goods use labor but not $H$, we may focus on the allocation of $H$ to imitation through catch-up or to innovation. Adopting a linear specification with $g\left(H_{i}\right)=g H_{i}, c\left(H_{i}\right)=c H_{i}$, the marginal product of $H$ in innovation is given by $g A_{i}(t)$ while in imitation, for the confined exponential case, it is $c A_{i}(t)\left(\frac{A_{m}(t)}{A_{i}(t)}-1\right)$. These are independent of $H_{i}$ so we may have a bang-bang solution, with all of $H_{i}$ allocated towards catch-up and imitation up to a threshold, and to innovation otherwise. In what follows we will, for he time

\footnotetext{
${ }^{7}$ We should note that $c\left(H_{i}\right)$ may also depend on barrers to innovation as in Parente and Prescott (1994), so that in fact we have $c\left(H_{i}, X\right)$, where $X$ represents the level of barriers.
} 
being, abstract from issues regarding the allocation of $H_{i}$, and assume that all of it enters both imitation and catch-up as a non-excludable public good.

\section{Some Microfoundations based on the diffusion model of Barro and Sala-i-Martin}

To set the stage first we express the confined exponential and logistic growth equations discussed above in stationary variables by defining

$$
B(t)=\frac{A_{i}(t)}{A^{*}(0)} e^{-g_{m} t}
$$

for all $i$. Then, for the logistic case, we have

$$
\begin{aligned}
\frac{\dot{B}}{B} & =c\left(H_{i}\right)(1-B)+g\left(H_{i}\right)-g\left(H_{m}\right) \\
\dot{B} & =\left(c\left(H_{i}\right)+g\left(H_{i}\right)-g\left(H_{m}\right)\right) B-c\left(H_{i}\right) B^{2}
\end{aligned}
$$

If $H_{i}^{\prime} s$ are fixed the solution is,

$$
B(t)=\left(\frac{c_{i}+g_{i}-g_{m}}{c_{i}}\right)\left[1+\left(\left(\frac{c_{i}+g_{i}-g_{m}}{c_{i}}\right)\left(\frac{A^{*}(0)}{A(0)}\right)-1\right) e^{-\left(\frac{c_{i}+g_{i}-g_{m}}{c_{i}}\right) t}\right]^{-1}
$$

So if $c_{i}+g_{i}-g_{m}>0$,

$$
\lim _{t \rightarrow \infty} B(t)=\left(\frac{c_{i}+g_{i}-g_{m}}{c_{i}}\right),
$$

while if $c_{i}+g_{i}-g_{m}<0, \lim _{t \rightarrow \infty} B(t)=0 .{ }^{8}$ Note from equation (3.2) that in the latter case where $c_{i}+g_{i}-g_{m}<0$, there is no steady state with $B>0$.

\footnotetext{
${ }^{8}$ In the case $c_{i}+g_{i}-g_{m}>0, B(t)$ should (if the assumption that $H_{i}^{\prime} s$ are constant holds) exhibit the S-shaped logistic diffusion.
} 
In the confined exponential case

$$
\begin{aligned}
& \frac{\dot{B}}{B}=c\left(H_{i}\right)\left(B^{-1}-1\right)+g\left(H_{i}\right)-g\left(H_{m}\right) \\
& \dot{B}=c\left(H_{i}\right)-\left(c\left(H_{i}\right)+g\left(H_{m}\right)-g\left(H_{i}\right)\right) B
\end{aligned}
$$

Since $c\left(H_{i}\right)+g\left(H_{m}\right)-g\left(H_{i}\right)>0$, it is clear from (3.4) that there exists a stable steady state at $B=\frac{c\left(H_{i}\right)}{c\left(H_{i}\right)+g\left(H_{m}\right)-g\left(H_{i}\right)}$.

In the Barro and Sala-i-Martin (1997) model, the North, where innovation is cheap, is the leader. It innovates by introducing new intermediate goods, and receives no diffusion through imitation from the South. As in a typical growth model of the Romer type, it grows at a constant rate $\gamma$. The South introduces new intermediate goods through imitation. In both countries the production of final goods is given by:

$$
Y_{i}=A_{i}\left(L_{i}\right)^{1-\alpha} \sum_{j=1}^{N_{i}}\left(X_{i j}\right)^{\alpha} \quad i=1,2
$$

where the North is country 1 and the South is country 2, so that $N_{1}>N_{2}$. The profits of the $j^{\prime}$ th intermediate goods producer is given by $\pi_{2 j}=\left(P_{2 j}-1\right) X_{2 j}$ where $P_{2 j}$ is the price of the intermediate good in terms of the final good in the South. The cost of imitation in the South is $v_{2}\left(\frac{N_{2}}{N_{1}}\right)$.In a symmetric equilibrium investment in $\mathrm{R} \& \mathrm{D}$ is given by

$$
v_{2} \dot{N}_{2}=Y_{2}-C_{2}-N_{2} X_{2}
$$

where the LHS is the cost of introducing a new intermediate good through imitation, and the RHS is income minus consumption minus the cost of operating the existing intermediate goods (since $X_{i 2}=X_{2}$ for all $i$ ). Barro and Sala-i-Martin show that in equilibrium $X_{2}$ and $\frac{Y_{2}}{N_{2}}$ are constants. ${ }^{9}{ }^{10}$ For simplicity of exposition

\footnotetext{
${ }^{9}$ In particular, $X_{2}=L_{2}\left(A_{2}\right)^{\frac{1}{1-\alpha}}(\alpha)^{\frac{2}{1-\alpha}}$ and $\frac{Y_{2}}{N_{2}}=\left(A_{2}\right)^{\frac{1}{1-\alpha}} \alpha^{\frac{2 \alpha}{1-\alpha}} L_{2}$ where $L_{2}$ is, for simplicity, the constant the labor supply in the South.

${ }^{10}$ In BSM, consumption growth depends on the interest rate, which reflects the value of the
} 
we will also assume a constant consumption propensity, so that $C_{2}=\mu Y_{2}$, so that

$$
\frac{\dot{N}_{2}}{N_{2}}=\frac{1}{v_{2}}\left(\frac{Y_{2}(1-\mu)}{N_{2}}-X_{2}\right) \equiv \frac{1}{v_{2}} P
$$

and

$$
\frac{\dot{B}}{B}=\frac{1}{v_{2}} P-\gamma
$$

where $B=\frac{N_{2}}{N_{1}}$.

Barro and Sala-i-Martin assume that

$$
v_{2}=\eta\left(\frac{N_{2}}{N_{1}}\right)^{\sigma} \equiv \eta B^{\sigma}
$$

Imitations costs are higher, the closer the follower is to the leader. We can now assume that $\eta$ depends negatively on human capital, so that the cost of imitation declines with $H$. Introducing this specification into (3.5) we get

$$
\dot{B}=\eta^{-1} B^{1-\sigma} P-\gamma B=B\left(\eta^{-1} P B^{-\sigma}-\gamma\right)
$$

which has a stable steady state at $B=\left(\frac{\eta \gamma}{P}\right)^{-\frac{1}{\sigma}}$. Therefore this specification of imitation costs yields the same qualitative conclusions as the confined exponential diffusion used by Nelson and Phelps: the leader acts as the engine of growth pulling the followers along.

We now modify the imitation costs to correspond to the case of logistic technology diffusion. Let

$$
v_{2}=\eta(1-B)^{-1}
$$

where again $v_{2}$ is increasing in $B$. Now the diffusion equation becomes

$$
\dot{B}=\eta^{-1} P(1-B) B-\gamma B=\left(\eta^{-1} P-\gamma\right) B-\eta^{-1} P B^{2}
$$

stream of profits divided by the cost of imitation. Since the cost of imitation depends on $N_{2} / N_{1}$, the dynamic system is two-dimensional in $N_{2} / N_{1}$ and $C_{2} / N_{1}$. For details, see Barro and Sala-iMartin (1997). 
which has the same logistic structure as (3.2). In particular, there is a positive steady state $B=\frac{\eta^{-1} P}{\eta^{-1} P-\gamma}$ only if $\eta^{-1} P>\gamma$ Otherwise $B$ converges to 0 . Note that since $\eta^{-1}$ is increasing in $H$, for sufficiently low levels of $H$ we may have $\eta^{-1} P<\gamma$ so that the South never catches up in growth rates. There may be incentives to accumulate human capital in such circumstances. If there are market imperfections in the accumulation of capital, or if $H$ mostly provides external effects, there may not exist sufficient market incentives for the accumulation of $H$, so that subsidies to education may be necessary.

\section{A nested specification}

We can also, for purposes of estimation, specify a diffusion process that nests the logistic and confined exponential diffusion processes. Using the definition of $B$ given in (3.1), we can modify (3.2) as

$$
\begin{aligned}
\frac{\dot{B}}{B} & =\frac{c\left(H_{i}\right)}{s}\left(1-B^{s}\right)+g\left(H_{i}\right)-g\left(H_{m}\right) \\
\dot{B} & =\left(\frac{c\left(H_{i}\right)+s g\left(H_{i}\right)-s g\left(H_{m}\right)}{s}\right) B-\frac{c\left(H_{i}\right)}{s} B^{s+1} \\
\dot{B} & =\left(\frac{c\left(H_{i}\right)+s g\left(H_{i}\right)-s g\left(H_{m}\right)}{s}\right) B\left(1-\left(\frac{B^{s}}{\left(1+\frac{s\left(g_{i}-g_{m}\right)}{c_{i}}\right)}\right)\right)
\end{aligned}
$$

with $s \in[-1,1]$. Note that if $s=1$, this specification collapses to the logistic, and if $s=-1$, it collapses to the confined exponential ${ }^{11}$. In its general form this is a Bernoulli equation, whose solution, when $H_{i}$ and $H_{m}$ are constants so that $c_{i}=c\left(H_{i}\right), g_{m}=g\left(H_{m}\right), g_{i}=g\left(H_{i}\right)$, is given by :

\footnotetext{
${ }^{11}$ See Richards (1959).
} 


$$
B(t)=\left(\frac{\left(1+\frac{s\left(g_{i}-g_{m}\right)}{c_{i}}\right)}{\left.\left(1+\left(\left(1+\frac{s\left(g_{i}-g_{m}\right)}{c_{i}}\right) B(0)^{-s}\right)-1\right) e^{-\left(c_{i}+s\left(g_{i}-g_{m}\right)\right) t}\right)}\right)^{\frac{1}{s}}
$$

Since the leader has more human capital, $H_{m}>H_{i}$, we have $g_{m}>g_{i}$. It follows that if either $c_{i}+s\left(g_{i}-g_{m}\right)>0$,or if $s<0$,

$$
\lim _{t \rightarrow \infty} B(t)=\left(1+\frac{s\left(g_{i}-g_{m}\right)}{c_{i}}\right)^{\frac{1}{s}},
$$

while if $\left(1+\frac{s\left(g_{i}-g_{m}\right)}{c_{i}}\right)<0$, and $s>0, \lim _{t \rightarrow \infty} B(t)=\lim _{t \rightarrow \infty} \frac{A_{i}(t)}{A_{m}(t)}=0{ }^{12}$ In the latter case, as noted in the previous section, the South never catches up and growth rates diverge.

\footnotetext{
${ }^{12}$ If $c_{i}$ and $g_{i}$ vary with time because $H_{i}$ changes with time, (4.1) is the classic Bernoulli equation which we can write as:

$$
\dot{B}=f(t) B+g(t) B^{s+1}
$$

where $f(t)=\frac{c\left(H_{i}(t)\right)}{s}+g\left(H_{i}(t)\right)-g\left(H_{m}(t)\right)$ and $g(t)=-\frac{c\left(H_{i}(t)\right)}{s}$ as in equation (4.2). The solution is:

$$
B(t)=\left(C e^{\phi(t)}+s e^{\phi(t)} \int e^{\phi(\tau)} g(\tau) d \tau\right)^{-\frac{1}{s}}
$$
}

where $\phi(t)=s \int f(\tau) d \tau$ and $C$ is an integration constant such that $C^{-\frac{1}{s}}=B(0)$. 
When $s \rightarrow 0$, the diffusion process converges to the Gompertz growth model ${ }^{13}$ :

$$
\begin{gathered}
B=\lim _{s \rightarrow 0}\left(1+\frac{s\left(g_{i}-g_{m}\right)}{c_{i}}\right)^{\frac{1}{s}} \exp \left(-e^{k-c_{i} t}\right)=\exp \left(\frac{\left(g_{i}-g_{m}\right)}{c_{i}}\right) \exp \left(-e^{k-c_{i} t}\right) \\
\dot{B}=c_{i} B e^{k-c_{i} t}=c_{i} B \ln \left(\frac{\exp \left(\frac{\left(g_{i}-g_{m}\right)}{c_{i}}\right)}{B}\right) \\
e^{k}=\left(\frac{\left(g_{i}-g_{m}\right)}{c_{i}}\right)-\ln (B(0)) . \text { So } \lim _{t \rightarrow \infty} B=\exp \left(\frac{\left(g_{i}-g_{m}\right)}{c_{i}}\right)>0
\end{gathered}
$$

To test this nested specification empirically we can specify it as:

$$
\Delta a_{i t}=\left(g+\frac{c}{s}\right) h_{i t}-\frac{c}{s} h_{i t}\left(\frac{A_{i t}}{A_{m t}}\right)^{s} .
$$

where $\Delta a_{i t}$ is the growth of TFP for country $i, h_{i t}$ is its initial or average human capital and $\left(\frac{A_{i t}}{A_{m t}}\right)$ is the ratio of the country's TFP to that of the leader. Note again that this specification nests the logistic $(s=1)$ and exponential $(s=-1)$ models. As discussed above, the values of $c, g$ and $s$ will determine whether a country will converge to the growth rate of the leader or whether the the growth rates will diverge. In particular, or our linear specification $c\left(h_{i t}\right)=c_{i}=$ $c h_{i t}, g\left(h_{i t}\right)=g_{i}=g h_{i t}$ and $g\left(h_{m t}\right)=g_{m}=g h_{m t}$, "the catch-up condition" for the growth rate of a country to converge to the growth rate of the leader becomes (for $s \in(0,1])$ :

$$
c^{*}=1+\frac{c}{s g}>\frac{h_{m t}}{h_{i t}}
$$

Countries for which $\left(\frac{h_{m t}}{h_{i t}}\right)>c^{*}$ will not converge to the leader's growth rate unless they invest in their human capital to reverse this inequality. ${ }^{14}$

\footnotetext{
${ }^{13}$ To see this note that, using LHopital's Rule, the right side of equation (4.3) collapses to $c_{i} B \ln \left(\frac{\exp \left(\frac{\left(g_{i}-g_{m}\right)}{c_{i}}\right)}{B}\right)$, which is the right hand side of (4.6).

${ }^{14}$ As noted earlier however te catch-up coefficient $c\left(h_{i t}\right)$ may depend on other institutional
} 


\section{Empirical Evidence}

\subsection{Measurement of Total Factor Productivity}

Data for real income and population growth were obtained from the Penn World Tables, version 6.1.Data for human capital, which is proxied by average years of schooling in the population above 25 years of age, was obtained from the updated version of the Barro Lee (1993) data set. Our sample consists of 85 countries with data for the period 1960-1995. We estimate this sample both as a cross-section of 35 years of growth and as a panel of five-year growth rates.

Physical capital stocks were calculated according to the method used in Klenow and Rodriguez-Clare (1997). Initial capital stocks are calculated according to the following formula

$$
\frac{K}{Y}_{1960}=\frac{I / Y}{\gamma+\delta+n}
$$

where $I / Y$ is the average share of physical investment in output from 1960 through $2000, \gamma$ represents the average rate of growth of output per capita over that period, $n$ represents the average rate of population growth over that period, and $\delta$ represents the rate of depreciation, which is set equal to 0.03. Given initial capital stock estimates, the capital stock of country $i$ in period $t$ satisfies

$$
K_{i t}=\sum_{j=0}^{t}(1-\delta)^{t-j} I_{i j}+(1-\delta)^{t} K_{1960} .
$$

Total factor productivity growth was estimated from a constant returns to scale Cobb-Douglas production function with the capital share set at $1 / 3$ and the labor share set at $2 / 3 .{ }^{15}$ For country $i$ in period $t$

$$
a_{i t}=y_{i t}-\frac{1}{3} k_{i t}-\frac{2}{3} l_{i t}
$$

factors in addition to human capital, like barriers to innovation as in Parente and Prescott (1994). In such a case we may want to modify the catch-up coefficient to $c_{i}=\alpha_{i} c h_{i t}$ where $\alpha_{i}$ reflects country speific barriers to innovation.

${ }^{15}$ Gollin (2002) estimates that the share of labor lies between 0.65 and 0.80 for a cross-section 
where $a_{i t}$ represents the long of total factor productivity, $y_{i t}$ represents the log of real output, $k_{i t}$ represents the log of the physical capital stock, and $l_{i t}$ represents the $\log$ of the population.

Total factor productivity estimates for 1960 and 1995, as well as estimates of average annual growth in total factor productivity over the period are shown in Table 1. The results seem pretty intuitive, as the Asian Tiger countries, including Taiwan, Singapore, Korea, Hong Kong and Thailand, lie notably at or near the top in terms of total factor productivity growth, while the five countries exhibiting the lowest growth in total factor productivity are Mozambique, Niger, Central African Republic, Nicaragua, and Zambia. All of these countries experienced negative total factor productivity growth over the sample period, as did Mali, Senegal, Venezuela, Togo and Cameroon. Out of this group of ten negative total factor productivity growth countries, only Venezuela's appearance is surprising, and that can probably be attributed to its buildup of physical capital for oil production. In the case of the five highest total factor productivity growth countries, our results would no doubt differ slightly if our sample included the Asia crisis of 1997. Nevertheless, the set of countries exhibiting high total factor productivity growth seems intuitive as well.

A simple scatter plot of initial human capital levels and subsequent total factor productivity growth over the estimation period is shown in Figure 1. The raw correlation between these two variables is clearly positive, suggesting that nations with larger initial human capital stocks tend to exhibit higher total factor productivity growth holding all else constant. There are a number of interesting outliers. The Asian tiger nations are noteworthy as nations that exhibited fast total factor productivity growth and began the estimation period with rela-

of world economies. Keller (2002) estimated TFP with both the factor shares used above and the capital and labor shares set equal to one-half and obtained similar ordinal rankings of total factor productivity levels across countries. 
tively stocks of initial human capital. ${ }^{16}$ On the other hand, there are a number of countries that exhibited total factor productivity declines that began the period with exceptionally low levels of initial human capital, including Mali, Niger, Togo, Mozambique, and the Central African Republic.

\subsection{Model Specification}

As discussed above, the following non-linear cross-sectional specification nests the exponential and logistic functional forms of technology diffusion

$$
\Delta a_{i}=b+\left(g+\frac{c}{s}\right) h_{i}-\left(\frac{c}{s}\right) h_{i}\left(\frac{A_{i}}{A_{m}}\right)^{s}+\varepsilon_{i}
$$

where $\Delta a_{i}$ represents the average annual growth rate in TFP of country $i, h_{i}$ represents the log of country $i^{\prime} s$ stock of human capital, $A_{i}$ represents the level of country $i^{\prime} s$ stock of TFP, $A_{m}$ represents the level of TFP of the leader nation, and $\varepsilon_{i}$ is an i.i.d. disturbance term. The coefficients to be estimated represent $b$, $\left(g+\frac{c}{s}\right),-\left(\frac{c}{s}\right)$, and $s$ respectively.

We are agnostic as to whether it is appropriate to include the constant term $b$. This term could be interpreted as exogenous technological progress that is independent of human capital and technology diffusion. It is difficult to envision any type of technological progress that would be common across our sample and completely independent of the levels of national human capital. In the case where "accidental technological progress" truly does take place, it is far more likely that it would appear in our error term as it would be confined to specific nations within our sample. Nevertheless, we report our estimation results both without and with the constant terms included as a measure of their robustness.

\footnotetext{
${ }^{16}$ It is unfortunate that our sample ends in 1995, because the Asian "tiger" nations suffered large declines in the 1997 crisis. However, we confirmed that total factor productivity growth of these nations was still exceptionally high for the Asian tiger nations for which longer 39 year data from 1960 to 1999 was available. This included all of the tigers except Singapore.
} 
Our model nests two alternative hypotheses. First, we have our Nelson-Phelps type model of technology diffusion, dependent on human capital and technological backwardness, that is of the confined exponential type. As we noted above, this model would correspond to the above specification with $s$ equal -1 . Second, we have our logistic specification for the technology diffusion process, which would correspond to $s$ being equal to 1 . We therefore estimate the above nested model to let the data determine the appropriate value of $s$.

Because our model is non-linear, we cannot use the differenced panel estimators for cross-country growth regressions that have become popular in the literature [e.g. Caselli, Esquivel and Lefort (1996), Easterly, Loayza and Montiel (1997), and Benhabib and Spiegel (2000)]. Instead, we estimate the nested specification above in a cross-sectional sample of long-term growth using maximum likelihood. In order to minimize problems with endogeneity, we use initial values for human capital stocks and initial total factor productivity. As we are comparing these initial values to the nations' subsequent growth experiences over the next 35 years, endogeneity issues are unlikely to be a problem.

We also conduct a number of robustness checks. First, there is a concern about the quality of initial human capital values as a proxy of the human capital stock available over the estimation period. Recall that our specification implies that human capital is a measure of a nation's capacity to conduct innovation activity (accounted by the first term in the specification), and technology adoption from abroad (captured by the second term in the specification). However, many of the nations in our sample exhibited dramatic growth in their human capital stocks over this period, as measured by average years of schooling. A number of nations, including Nepal, Togo, Iran, Ghana, Syria, and the Central African Republic, actually had more than a five-fold increase in their average years of schooling in the population over the age of 25 . This implies that the initial stocks of human capital in 1960 may poorly represent the stocks of human capital available to 
a nation later on in the sample period. We therefore also report results using average human capital levels over the estimation period. ${ }^{17}$ However, this measure is likely to suffer more from endogeneity issues than initial human capital levels, as a nation's financial ability to increase the average human capital levels of its citizens is likely to be increasing in its rate of output and total factor productivity growth. Fortunately, as we demonstrate below, our results are fairly robust to either measure of the stock of human capital.

Second, since we are estimating a cross-section, we are unable to condition on country-specific fixed effects. In response, we further examine the robustness of our results to the introduction of a number of conditioning variables. Using data obtained from Sachs and Warner (1997), we introduce a number of geo-political characteristics, including a Sub-Saharan Africa dummy, a dummy for countries that are not landlocked, a dummy for tropical countries, a dummy for initial life expectancy, a dummy for ethnolinguistic fractionalization, and a dummy for openness over the estimation period.

\subsection{Results}

\subsubsection{Base specification}

Our results with initial stocks of human capital are shown in Table 2. Our base specification is reported in Model 1. It can be seen that the coefficient on human capital, which represents $(g+c / s)$ in the specification above, enters significantly with a positive coefficient in log levels at a 5 percent confidence level, consistent with the notion of human capital as a facilitator of own innovation predicted by the theory. The next term represents the coefficient on the catch-up term, $-(c / s)$ in the above specification. This term enter as predicted with a negative and

\footnotetext{
${ }^{17}$ Average human capital levels are calculated as the simple averages of beginning (1960) and ending (1995) human capital levels.
} 
statistically significant sign at a five-percent confidence level. Finally, our point estimate of $s$ is equal to 2.304. This number is not significantly different from 1 , but is significantly greater than 0 at a ten percent confidence level. These results therefore favor the logistic specification, suggesting that there is some initial human capital level below which a country would fall farther and farther behind the leader national in total factor productivity over time. We investigate this possibility in more detail below.

One disappointing result in our base specification is that our point estimate for human capital lies below that of the catch-up term in absolute value. This implies that our point estimate for $g$ is negative, which is implausible. However, this point estimate is insignificantly different from 0 and does include positive values for any standard confidence level. Nevertheless, the negative point estimate does become a problem for our data exploration. In particular, using the negative point estimate for $g$ precludes the existence of a positive critical human capital stock below which catch up in total factor productivity cannot occur.

As discussed above, the problem with the specification of Model 1 is that our theory does not call for for the a constant term independent of human capital to account for total factor productivity growth. Consequently, Model 2 repeats our base specification with the constant term excluded. It can be seen that our qualitative results are robust to the exclusion of a constant term. Human capital in log levels again enters significantly with a positive coefficient at a 5 percent confidence level, while the catch-up term is again significantly negative at a 5 percent confidence level, as predicted by the theory. Our point estimate of $s$ is a little higher, at 3.164, but as before we cannot reject the hypothesis that $s$ is equal to 1 at standard confidence levels, although we again reject the hypothesis that $s$ is less than or equal to 0 at a 10 percent confidence level. Moreover, it can be seen that our point estimate for $g$ is positive with this specification, allowing us to calculate a critical human capital stock below which catch-up in growth rates 
will not occur.

Models 3 and 4 repeat our estimation with and without a constant term, with $s$ constrained to equal 1 . This results in a linear specification and provides a robustness check of the coefficients obtained in our non-linear specification. It can be seen that our point and standard error estimates are very close to those obtained with $s$ unconstrained. Both with and without a constant term, human capital enters significantly with a positive coefficient in $\log$ levels at a 5 percent confidence level. Moreover, the catch-up term coefficient is again negative and significant at a 5 percent confidence level, as predicted. These results suggest that our findings are not dependent on the non-linear estimation of $s$ to obtain coefficient estimates consistent with the notion of human capital playing a positive role in facilitating both innovation and catch-up.

\subsubsection{Average human capital levels}

Our first set of robustness checks repeats our estimation using average levels of human capital over the estimation period rather than initial human capital values. ${ }^{18}$ As discussed above, we do this to address the concern some nations' stocks of human capital changed dramatically over the estimation period, and therefore that initial human capital values may be relatively noisy indicators of the average levels of human capital over the estimation period that determined their TFP growth .

The results incorporating this change are shown in Table 3. It can be seen that our qualitative results are fairly robust. Average human capital levels enter positively and significantly, as predicted, at a 5 percent confidence level, as do the coefficient estimates for the catch-up term. The magnitudes of these coefficients are similar to those obtained with initial human capital stocks, but they are both somewhat larger in absolute value. This increase is interesting because average

\footnotetext{
${ }^{18}$ Average stocks are estimated using simple averages of period beginning and ending values.
} 
measured human capital levels are larger than initial human capital levels, as all nations experienced some increase in average years of schooling over the estimation period.

Our estimates of $s$ in Models 1 and 2 are very close to 1, which would again favor our logistic specification, but the large standard errors associated with our estimates of $s$ leave it insignificantly different from 0 at standard confidence levels.

\subsubsection{Conditioning on Country Characteristics}

Because we are estimating a cross-section, we obviously are precluded from using panel estimators, such as country fixed and random effects, to control for differences in country characteristics outside of our theory that may independently influence total factor productivity growth. To account for these other possible influences, we introduce a number of conditioning variables into our specification from the Sachs and Warner (1997) data set. ${ }^{19}$ The conditioning variables introduced are Sub-Sahara, a dummy indicating Sub-Saharan African nations, Landlocked, a dummy indicating a nation lacking navigable access to the sea, Tropics, a variable measuring the share of land area subject to a tropical climate, Life, the log of life expectancy at birth measured between 1965 and 1970, Ethling, a measure of ethno-linguistic fractionalization, and Openness, an indicator of the degree to which domestic policy favors free trade.

We first present our results with all of the conditioning variables included, and then sequentially drop the Sub-Sahara and Openness variables. Our results are shown in Table 4. Note that the inclusion of these conditioning variables reduces our sample size from 84 to 75 countries. Models 1 and 2 report our results for our base specifications with all of the conditioning variables included. It can be seen that human capital in log levels is not positive at a statistically significant level in either specification. This result is attributable more to a substantial increase

\footnotetext{
${ }^{19}$ See Sachs and Warner (1997) for original data sources.
} 
in our standard error estimate rather than a change in the point estimate of the coefficient, which does not change much in value. On the other hand, it appears that the catch-up term is robust to the inclusion of these conditioning variables, as it enters significantly with a negative coefficient at a five percent confidence level, as predicted. Finally, our point estimates of $s$ are still close to 1 . We cannot reject that $s$ is negative at standard confidence levels when our intercept term is included, but we can with it excluded (Model 2). ${ }^{20}$

Models 3 and 4 omit the Sub-Sahara dummy. It can be seen that human capital in log levels is still insignificant when the constant term is included, but is now significant at a 10 percent confidence level when the constant term is excluded. The catch-up term is still significantly negative at a 5 percent confidence level, as predicted. Our point estimates for $s$ are still close to 1, with $s$ entering significantly with a greater than zero coefficient at a 10 percent confidence level with and without the inclusion of a constant term.

Finally, Models 5 and 6 omit the Openness variable. Human capital in log levels is insignificant with the constant term included, but is positive and significant, as predicted, with the exclusion of the constant term at a 10 percent confidence level. The catch-up term is still significantly negative at a 5 percent confidence level, as predicted. Our point estimates for $s$ are again close to 1, although $s$ is insignificantly different from zero both with and without the inclusion of a constant term in our specification.

In summary, it appears that the catch-up term is strongly robust to the inclu-

${ }^{20}$ To determine whether the differences here were attributable to the inclusion of the conditioning variables or the reduction in sample size, we estimated our models with the smaller 75 country sample reported here with the conditioning variables excluded. We obtained similar results to those in the larger sample. In particular, we obtained a positive and significant coefficient on human capital in log levels. This indicates that the differences in results reported here are attributable to the inclusion of the conditioning variables. 
sion of the conditioning variables, while the estimates of $s$ are still close to one, but of mixed significance. It would therefore be fair to characterize these coefficient estimates to be fairly robust to the inclusion of the conditioning variables. ${ }^{21}$ However, human capital in log levels was somewhat less robust This result may not be surprising for a number of reasons: First, the conditioning variables, such as initial life expectancy and subsequent openness, are likely to be correlated with initial human capital levels. Indeed, initial life expectancy may be considered to be an alternative indicator of investment in human capital for many developing countries. Second, Benhabib and Spiegel (1994) found that initial human capital, which determines the rate of own-country innovation, was unimportant for a sub-sample of poorer developing countries. The introduction of our conditioning may have exposed the relatively weak role that innovation plays in total factor productivity growth for the poorer nations in our sample. ${ }^{22}$

\footnotetext{
${ }^{21}$ To investigate the possibility that technological catch-up was facilitated by other variables than human capital, we substituted our Life and Openness conditioning variables for human capital in our base specification. The estimate for $s$ was positive, but insignificant in all specifications. The coefficients on Life, both on their own and interacted with backwardness, were consistent with the theory and significant with the constant term included, but insigifnicant with it excluded. The coefficients on Openness, however, both on their own and interacted with backwardness, were very insignificant. As a whole, this exercise provided weak evidence of robustness for the logistic specification. Yet the imprecision of our measurements and the high correlation between country characteristic measures makes it difficult to evaluate the precise contribution of human capital relative to other potential institutuional characteristics that can facilitate catch-up. For example, the correlation coefficient between $h_{i 60}$ and Life is 0.85 . These results are available from the authors on request.

${ }^{22}$ We also examined the robustness of our results to splitting the sample with the conditioning variables included. We split the sample into OECD and non-OECD nations. Our coefficient values for both sub-samples were of the correct sign and significant. However, we also found that the point estimate of the innovation term was larger for the OECD sub-sample, while that
} 


\section{Model Prediction}

\subsection{Model Forecasting}

Given a nation's initial values of $H_{i 60}$ and $B_{i}(60)$, our transition equation 4.4 gives us a predicted value of $B$ at the end of our sample in 1995 . Figure 2 displays the predicted values of $B_{i}(95)$ conditional on $H_{i 60}$ and $B_{i}(60)$. One can see the logistic "s" form, consistent with a logistic model of technology diffusion, of our predicted values from our estimation above. Countries which have both low initial total factor productivity relative to the leader and low levels of human capital are in the low-growth portion of the plane: their predicted 1995 total factor productivity levels relative to the leader lie close to, or even below, their 1960 values. There is then a rapid acceleration in the middle range, tapering off as nations approach the total factor productivity levels of the leader.

We show both the actual realizations and the predictons of our model in Figure 3. Expected values of $B_{i}(95)$ for the nations in our sample based on equation 4.4 are plotted against their realized values in 1995. The model does a fairly good job of predicting relative future productivity levels. As a measure of our goodness of fit, we calculated the coefficient of determination of the model. The ratio of residual sum-of-squared errors to the variation in the sample was only, 0.115 , which would correspond to an R-squared of 88.5 percent.

However, there does appear to be some systematic errors in our forrecasts. In particular, we seem to be systematically overestimating relative total factor productivity growth for the least backward, highest initial productivity countries like the Asian Tigers, so that the residuals for these countries are nearly all neg-

for the catch-up term was larger in absolute value for the non-OECD sample. This supports our findings in Benhabib and Spiegel (1994) that innovation is more important for the developed countries, while catch-up is more important for the developing nations. These regression results are also available upon request from the authors. 
ative. This result, which suggests an even more prounced 's' curve, is puzzling, but appears to leave room for future refinements in our theory.

\subsection{Negative Catch-up Countries}

A more qualitative metric of the quality of fit of our model is how well it makes the discrete prediction of whether coutries will be on a positive catch-up path or not. The theory above suggests that below a certain threshold level of human capital, relative to the leader nation, a country could find its total factor productivity growth sufficiently slow that it would not exhibit convergence in total factor productivity, but would instead fall farther and farther behind the leader nation over time. In particular, we can re-write the "catch-up condition" in equation 4.7 as

$$
H_{i t}^{*}=\exp \left(\frac{s g h_{m t}}{s g+c}\right)
$$

where $h_{m t}$ represents the log of human capital in the leader nation at time $t$. Countries that find themselves with human capital stocks below $H_{i t}^{*}$ will experience total factor productivity growth at a slower pace than the leader country.

Table 5 shows the point estimates for $g, c$, and $s$ based on our estimation results for models 1 through 4 in Tables 2 and 3. As we discussed above, we cannot calculate a critical human capital stock for Model 1 in Table 2 because of our negative point estimate for $g$. Consequently, we concentrate on the point estimates obtained in Model 2 of Table 2, where the specification excludes a constant term independent of human capital. As we show below, our estimates of the critical human capital stocks are similar for all of our models.

With the United States as our leader in total factor productivity, the point estimates obtained with Model 2 indicate that countries with average schooling in the population over the age of 25 below 1.78 years will display slower total factor productivity growth than the leader nation. We note that the critical human 
capital stocks were relatively insensitive to model specification or the use of initial or average human capital levels.

Similarly, we can also calculate the average years of schooling in the population needed to experience faster total factor productivity growth than the United States in 1995. Because of the increase in average years of schooling in the United States, the point estimates for $H_{i 95}^{*}$ are uniformly larger than those for $H_{i 60}^{*}$. Again using our point estimates from Model 2, we estimate the critical level of average years of schooling in the population to be 1.95. This increase in the threshold level of human capital is due to the fact that with a larger stock of human capital, the leader nation will be innovating at a faster pace. Consequently, other nations will need to exhibit a faster pace of catch-up to experience faster total factor productivity growth than the leader.

We use these estimated critical human capital stocks to conduct 2 explorations in the data. First, we can identify nations in our sample that would be predicted to exhibit slower growth in total factor productivity than the United States in 1960. This would include all nations with human capital levels in 1960 below 1.78 years of schooling. Our results are shown in Table 2. Based on our point estimates, we identify 27 nations as being below the critical human capital stock level in 1965. These nations are listed in Table 6, along with their average initial human capital stock levels.

The second column examines the growth performance of these nations over the subsequent 35 years in our sample. While it is not a formal test of our model, it is rather striking that 22 of the 27 nations predicted to exhibit slower total factor productivity growth than the United States actually did so over the course of our sample. This is markedly different than the overall sample share, where 49 of the 84 countries exhibited faster total factor productivity growth than the United States. Consequently, the subsequent performance of these nations appears to support the possibility of a logistic form of technology diffusion. 
Our second data exploration concerns the question of whether there are any nations that are still below the critical human capital stock, so that they are expected to have slower total factor productivity growth than the United States in the future. We investigate this question using our 1995 data. As mentioned above, the critical human capital stock using any model specification is estimated to have increased slightly between 1960 and 1995, from 1.78 average years of schooling to 1.95. Nevertheless, the good news is that because many developing nations have made substantial efforts to increase primary education rates in their populations, there are few countries who failed to meet this criterion in 1995.

The four nations that fell below the critical human capital level in 1995 are listed in Table 7. They are Mali, Niger, Mozambique and Nepal. While the success of the rest of the world in acquiring sufficient human capital to be on positive catch-up path in total factor productivity is reassuring, the situation faced by these four nations is still alarming. As shown in Table 7, none of these nations has a total factor productivity level exceeding 15 percent of that in the United States. In contrast, the average ratio of the total factor productivity of a nation in our sample to that of the United States is approximately 44 percent. Our model therefore predicts that these nations will remain notably poor in the absence some sort of policy intervention.

\section{Conclusion}

This paper generalizes the Nelson-Phelps catch-up model of technology diffusion facilitated by levels of human capital. We allow for the possibility that the pattern of technology diffusion is exponential. This specification predicts that nations will exhibit positive catch-up in growth rates. In contrast a logistic diffusion specification implies that a country with a sufficiently small capital stock may exhibit slower total factor productivity growth than the leader nation.We 
then derive a nonlinear specification for total factor productivity growth that nests these two specifications. We test this specification for a cross-section of 84 countries. Our results favor the logistic specification over the exponential, and other estimated parameters are consistent with our theoretical predictions. The catch-up term in our specification is robust to a number of sensitivity checks, including the use of average rather than initial levels of human capital and the inclusion of a variety of geo-political conditioning variables commonly used in the literature. This supports the notion that human capital plays a positive role in the determination of total factor productivity growth rates through its influence on the rate of catch-up. However, the direct performance of the human capital term on its own is somewhat less robust.

Using the coefficient estimates from our parametric estimation, we then calculate the critical human capital stocks needed to achieve positive total factor productivity growth in 1960 and 1995 . Our results identify 27 nations as falling below the critical human capital level in 1960, while only 4 nations remain below the critical human capital level in 1995.

The historic experiences of these nations support our theory well. 22 of the 27 nations predicted to have slower growth than the leader nation (the United States) actually did so over the subsequent 35 years. This contrasts markedly with the overall experience of the nations in our sample, where 49 of the 84 nations experienced faster total factor productivity growth than the leader nation. 


\section{References}

[1] Acemoglu, Daron (2002), "Factor Prices and Technical Change," in Philippe Aghion ed., Festschrift in Honor of Edmund Phelps, forthcoming.

[2] Aghion, Philippe, Christopher Harris and Johnathan Vickers (1997), "Competition and Growth with Step-by-Step Innovation: An Example," European Economic Review, April 1997, 41(3-5), 771-82

[3] Banks, Robert B. (1994), Growth and Diffusion Phenomena, (Springer Verlag, Berlin).

[4] Barro, Robert J. and Jong Wha Lee. (1993), "International Comparisons of Educational Attainment," Journal of Monetary Economics, 32, 363-394.

[5] Barro, Robert J., and Xavier Sala-i-Martin, (1995), Economic Growth,

[6] Barro, Robert J., and Xavier Sala-i-Martin, (1997), "-Technological Diffusion, Convergence and Growth," Journal of Economic Growth, 1, 1-26

[7] Bartel, Ann P, and Frank R. Lichtenberg, (1987), "The Comparative Advantage of Educated Workers in Implementing New Technology," Review of Economics and Statistics, February, 69(1), 1-11.

[8] Basu, Susanto, and David N. Weil, (1998), "Appropriate Technology and Growth," Quarterly Journal of Economics, November, 113(4), 1025-54.

[9] Benhabib, Jess and Mark M. Spiegel. (1994), "The Role of Human Capital in Economic Development: Evidence from Aggregate Cross-Country Data," Journal of Monetary Economics, 34, 143-173. 
[10] Benhabib, Jess and Mark M. Spiegel, (2000), "The Role of Financial Development in Growth and Investment," Journal of Economic Growth, 5, 341-360.

[11] Bils, Mark, and Peter J. Klenow, (2000), "Does Schooling Cause Growth?," American Economic Review, December, 90(5), 1160-83.

[12] Branstetter, Lee G., (2001), "Are Knowledge Spillovers International or Intranational in Scope? Microeconometric Evidence from the U.S. and Japan," Journal of International Economics, February, 53(1), 53-79.

[13] Caselli, Francesco, Gerardo Esquivel, and Fernando Lefort. (1996), "Reopening the Convergence Debate: A New Look at Cross-Country Growth Empirics," Journal of Economic Growth, 1, 363-390.

[14] Coe, David T. and Elhanan, (1995), "International R\&D Spillovers," European Economic Review, May, 39(5), 859-87

[15] Durlauf, Steven, N. and Paul A. Johnson, (1995), "Multiple Regimes and Cross-Country Growth Behavior," Journal of Applied Econometrics, 365384.

[16] Duffy, Johnathan and Christopher Papageorgiou, (2000), "A Cross-Country Empirical Investigation of the Aggregate Production Function Specification," Journal of Economic Growth, 5, 87-120.

[17] Eeckhout, Jan and Boyan Jovanovic, (2000), "Knowledge Spillovers and Inequality." American Economic Review 92, no. 5. 
[18] Easterly, William, Norman Loayza, and Peter Montiel. (1997), "Has Latin America's Post-Reform Growth Been Disappointing?," Journal of International Economics, 43, 287-311.

[19] Foster, Andrew D. and Mark R. Rosenzweig, (1995), "Learning by Doing and Learning from Others: Human Capital and Technical Change in Agriculture," Journal of Political Economy, December, 103(6), 1176-1209.

[20] Gerschenkron, A., (1962), Economic backwardness in historical perspective, Cambridge, Belknap Press of Harvard University Press.

[21] Griliches, Zvi, (1992), "The Search for R\&D Spillovers," Scandinavian Journal of Economics, 94, 29-47.

[22] Grossman, Gene M. and Elhanan Helpman, (1991), "Trade, Knowledge Spillovers and Growth," European Economic Review, 35, 517-26.

[23] Hall, Robert E. and Charles I. Jones, (1999), "Why Do Some Countries Produce So Much More Output Per Worker Than Others?," Quarterly Journal of Economics, February, 114(1), 83-116

[24] Hanushek, Eric A. and Dennis D. Kimko, (2000), "Schooling, Labor-Force Quality, and the Growth of Nations," American Economic Review, December, 90(5), 1184-1208

[25] Helpman, Elhanan, (1993), "Innovation, Imitation, and Intellectual Property Rights," Econometrica, 61, 1247-80. 
[26] Howitt, Peter and David Mayer-Foulkes, (2002) "R\&D, Implementation and Stagnation: A Schumpeterian Theory of Convergence Clubs," NBER Working Paper Series, no. 9104, Cambridge.

[27] Islam, Nazrul. (1995). "Growth Empirics: A Panel Data Approach," Quarterly Journal of Economics, 110, 1127-1170.

[28] Kyriacou, George, (1991), "Level and Growth Effects of Human Capital," C.V. Starr Center Working Paper no. 91-26.

[29] Klenow, Peter J., and Andrés Rodriguez-Clare, (1997), "The Neoclassical Revival in Growth Economics: Has It Gone Too Far?," N.B.E.R. Macroeconomics Annual, 73-103.

[30] Krueger, Alan B. and Mikael Lindahl, (2001), "Education for Growth: Why and for Whom?," Journal of Economic Literature, December, 39(4), 1101-36

[31] Mansfield, Edwin, (1968), Industrial Research and Technogical Innovation, Norton, New York.

[32] Nadiri, M. Ishaq, and Seongjun Kim, (1996), "International R\&D Spillovers, Trade and Productivity in Major OECD Countries," N.B.E.R. Working Paper no. 5801, October.

[33] Nelson, Richard R. and Edmund S. Phelps (1966), "Investment in Humans, Technological Diffusion, and Economic Growth," American Economic Review, 56, 69-75.

[34] Parente, Stephen L.., and E. C. Prescott, "Barriers to Technology Adoption and Development," Journal of Political Economy, 102 (1994), 298-321, 
[35] Pritchett, L. (1996), "Where has all the education gone?", World Bank Policy Research Working Paper \#1581

[36] Psacharopoulos, George, and Ana Maria Arriagada (1986), "The Educational Attainment of the Labor Force: An International Comparison," International Labor Review, 125(5), 561-574.

[37] Richards, F.J., (1959), "A Flexible Growth Function for Empirical Use," Journal of Experimental Botany, 290-300

[38] Romer, P., (1990), "Endogenous Technical Change," Journal of Political Economy, 98, S71-S102.

[39] Sachs, Jeffrey. D. and Andrew M. Warner, (1997), "Fundamental Sources of Long-Run Growth,". American Economic Review, May, 87(2), 184-188.

[40] Segerstrom, P., (1991), "Innovation, Imitation, and Economic Growth," Journal of Political Economy, 94, 1163-1190.

[41] Sharif and Ramanthran (1981), "Binomial Innovation Diffusion Models with Dynamic Potential Adopter Population, Technological Forecasting and Social Change 20, 63-87.

[42] Temple, Jonathan, "The New Growth Evidence," Journal of Economic Literature, March, 37(1), 112-56.

[43] Welch, Finis, (1975), "Human Capital Theory: Education, Discrimination, and Life Cycles," American Economic Review, May, 65(2), 63-73. 
Table 1

Total Factor Productivity Estimates (1960-1995)

\begin{tabular}{|c|c|c|c|}
\hline Country & $\log \mathrm{TFP}_{1960}$ & $\log \mathrm{TFP}_{1995}$ & $\begin{array}{l}\text { avg annual log growth } \\
\text { of TFP (1960-1995) }\end{array}$ \\
\hline Mozambique & 0.5010 & -0.0353 & -0.0153 \\
\hline Niger & 0.2045 & -0.2983 & -0.0144 \\
\hline Central African Rep. & 0.4180 & -0.0791 & -0.0142 \\
\hline Nicaragua & 0.4487 & 0.0546 & -0.0113 \\
\hline Zambia & -0.2912 & -0.5857 & -0.0084 \\
\hline Mali & -0.1092 & -0.2677 & -0.0045 \\
\hline Senegal & 0.3209 & 0.1634 & -0.0045 \\
\hline Venezuela & 1.0141 & 0.9306 & -0.0024 \\
\hline Togo & -0.1249 & -0.1917 & -0.0019 \\
\hline Cameroon & 0.3181 & 0.2649 & -0.0015 \\
\hline Tanzania & -1.0572 & -1.0181 & 0.0011 \\
\hline Bolivia & 0.3817 & 0.4642 & 0.0024 \\
\hline Honduras & 0.1513 & 0.2597 & 0.0031 \\
\hline El Salvador & 0.7495 & 0.8820 & 0.0038 \\
\hline Guyana & 0.0168 & 0.1989 & 0.0052 \\
\hline Peru & 0.4039 & 0.6054 & 0.0058 \\
\hline Argentina & 0.9538 & 1.1675 & 0.0061 \\
\hline Uganda & 0.0519 & 0.2721 & 0.0063 \\
\hline South Africa & 0.8463 & 1.0689 & 0.0064 \\
\hline Jamaica & 0.2297 & 0.4554 & 0.0064 \\
\hline Philippines & 0.2176 & 0.4506 & 0.0067 \\
\hline Costa Rica & 0.6131 & 0.8480 & 0.0067 \\
\hline Bangladesh & -0.0997 & 0.1442 & 0.0070 \\
\hline Jordan & 0.4289 & 0.6773 & 0.0071 \\
\hline New Zealand & 1.1840 & 1.4505 & 0.0076 \\
\hline Uruguay & 0.8978 & 1.1733 & 0.0079 \\
\hline Nepal & -0.3250 & -0.0416 & 0.0081 \\
\hline Malawi & -0.7672 & -0.4742 & 0.0084 \\
\hline Algeria & 0.3615 & 0.6622 & 0.0086 \\
\hline Ghana & -0.2121 & 0.0893 & 0.0086 \\
\hline Guatemala & 0.5197 & 0.8215 & 0.0086 \\
\hline Switzerland & 1.2467 & 1.5526 & 0.0087 \\
\hline Kenya & -0.2842 & 0.0390 & 0.0092 \\
\hline
\end{tabular}




\begin{tabular}{|c|c|c|c|}
\hline Country & $\log \mathrm{TFP}_{1960}$ & $\log \mathrm{TFP}_{1995}$ & $\begin{array}{l}\text { avg annual log growth } \\
\text { of TFP (1960-1995) }\end{array}$ \\
\hline Mexico & 0.6282 & 0.9549 & 0.0093 \\
\hline Papua New Guinea & 0.3175 & 0.6532 & 0.0096 \\
\hline Iran & 0.3787 & 0.7390 & 0.0103 \\
\hline Lesotho & -0.4715 & -0.1054 & 0.0105 \\
\hline Trinidad \&Tobago & 0.8535 & 1.2695 & 0.0119 \\
\hline Fiji & 0.3940 & 0.8118 & 0.0119 \\
\hline Ecuador & 0.1191 & 0.5526 & 0.0124 \\
\hline Sweden & 1.0855 & 1.5350 & 0.0128 \\
\hline Dominican Rep. & 0.2220 & 0.6859 & 0.0133 \\
\hline United Kingdom & 1.1090 & 1.5778 & 0.0134 \\
\hline Canada & 1.1711 & 1.6541 & 0.0138 \\
\hline Australia & 1.1472 & 1.6339 & 0.0139 \\
\hline Denmark & 1.1227 & 1.6215 & 0.0143 \\
\hline Paraguay & 0.4728 & 0.9894 & 0.0148 \\
\hline Turkey & 0.4371 & 0.9546 & 0.0148 \\
\hline Colombia & 0.4648 & 0.9855 & 0.0149 \\
\hline Netherlands & 1.0327 & 1.5617 & 0.0151 \\
\hline Zimbabwe & -0.2344 & 0.2948 & 0.0151 \\
\hline United States & 1.3257 & 1.8626 & 0.0153 \\
\hline Sri Lanka & 0.0648 & 0.6074 & 0.0155 \\
\hline Finland & 0.8676 & 1.4237 & 0.0159 \\
\hline Iceland & 0.9602 & 1.5301 & 0.0163 \\
\hline Chile & 0.6381 & 1.2141 & 0.0165 \\
\hline India & -0.2360 & 0.3458 & 0.0166 \\
\hline Panama & 0.2486 & 0.8324 & 0.0167 \\
\hline France & 0.9176 & 1.5088 & 0.0169 \\
\hline Ireland & 0.8202 & 1.6031 & 0.0182 \\
\hline Belgium & 0.9147 & 1.5555 & 0.0183 \\
\hline Syria & 0.1391 & 0.7957 & 0.0188 \\
\hline Brazil & 0.2618 & 0.9204 & 0.0188 \\
\hline Greece & 0.5097 & 1.1877 & 0.0194 \\
\hline Austria & 0.8583 & 1.5445 & 0.0196 \\
\hline Norway & 0.8808 & 1.5879 & 0.0202 \\
\hline Italy & 0.8291 & 1.5379 & 0.0202 \\
\hline Israel & 0.7494 & 1.4757 & 0.0163 \\
\hline Pakistan & -0.4390 & 0.3175 & 0.0216 \\
\hline
\end{tabular}




\begin{tabular}{cccc}
\hline Country & $\log$ TFP $_{1960}$ & $\log$ TFP $_{1995}$ & $\begin{array}{c}\text { avg annual log growth } \\
\text { of TFP (1960-1995) }\end{array}$ \\
\hline Spain & 0.6153 & 1.4203 & 0.0230 \\
Mauritius & 0.6394 & 1.4829 & 0.0241 \\
Portugal & 0.4739 & 1.3254 & 0.0243 \\
Indonesia & -0.1621 & 0.7056 & 0.0248 \\
Barbados & 0.5475 & 1.4540 & 0.0259 \\
Malaysia & 0.2549 & 1.1852 & 0.0266 \\
Romania & -0.3987 & 0.5327 & 0.0266 \\
Japan & 0.5632 & 1.5851 & 0.0292 \\
Botswana & -0.1326 & 0.9935 & 0.0322 \\
Cyprus & 0.3582 & 1.5217 & 0.0332 \\
Thailand & -0.3058 & 0.9102 & 0.0347 \\
Hong Kong & 0.4578 & 1.8604 & 0.0401 \\
Rep. of Korea & -0.0429 & 1.3646 & 0.0402 \\
Singapore & 0.1202 & 1.6285 & 0.0431 \\
Rep. of China, Taiwan & 0.1046 & 1.6140 & 0.0431 \\
\hline
\end{tabular}


Table 2

Regression Results: Log $H_{1960}$

\begin{tabular}{|c|c|c|c|c|}
\hline & Model 1 & Model 2 & Model 3 & Model 4 \\
\hline$C$ & $\begin{array}{c}0.0083^{* *} \\
(0.0016)\end{array}$ & - & $\begin{array}{c}0.0085^{* *} \\
(0.0016)\end{array}$ & - \\
\hline $\ln \left(H_{1960}\right)$ & $\begin{array}{c}0.0080^{* *} \\
(0.0019)\end{array}$ & $\begin{array}{c}0.0116 * * \\
(0.0016)\end{array}$ & $\begin{array}{c}0.0100 * * \\
(0.0023)\end{array}$ & $\begin{array}{c}0.0134^{* *} \\
(0.0025)\end{array}$ \\
\hline $\ln \left(H_{1960}\right) *\left(\frac{T F P_{i}}{T F P_{m}}\right)^{s}$ & $\begin{array}{c}-0.0086^{* *} \\
(0.0032)\end{array}$ & $\begin{array}{c}-0.0085^{* *} \\
(0.0039)\end{array}$ & $\begin{array}{c}-0.0089 * * \\
(0.0036)\end{array}$ & $\begin{array}{r}-0.0072^{* *} \\
(0.0025)\end{array}$ \\
\hline$s$ & $\begin{array}{l}2.304^{*} \\
(1.405)\end{array}$ & $\begin{array}{l}3.164^{*} \\
(1.892)\end{array}$ & 1 & 1 \\
\hline \# of observations & 84 & 84 & 84 & 84 \\
\hline log likelihood & 264.5 & 252.4 & 263.9 & 263.9 \\
\hline Wald P-value & 0.00 & 0.00 & 0.00 & 0.00 \\
\hline
\end{tabular}

note: Estimation by maximum likelihood with standard errors presented in parentheses. ${ }^{* *}$ denotes statistical significance at the $5 \%$ confidence level while $*$ denotes statistical significane at the $10 \%$ confidence level. 
Table 3

Regression Results: $\log \bar{H}_{1960-1995}$

\begin{tabular}{|c|c|c|c|c|}
\hline & Model 1 & Model 2 & Model 3 & Model 4 \\
\hline$C$ & $\begin{array}{l}-0.0030 \\
(0.0024)\end{array}$ & - & $\begin{array}{l}-0.0030 \\
(0.0024)\end{array}$ & - \\
\hline $\ln \left(\bar{H}_{1960-1995}\right)$ & $\begin{array}{c}0.0175^{* *} \\
(0.0046)\end{array}$ & $\begin{array}{c}0.0150^{* *} \\
(0.0039)\end{array}$ & $\begin{array}{c}0.0184^{* *} \\
(0.0026)\end{array}$ & $\begin{array}{c}0.0159^{* *} \\
(0.0017)\end{array}$ \\
\hline $\ln \left(\bar{H}_{1960-1995) *\left(\frac{T F P_{i}}{T F P_{m}}\right)^{s}}\right.$ & $\begin{array}{c}-0.0129 * * \\
(0.0039)\end{array}$ & $\begin{array}{c}-0.0116 * * \\
(0.0036)\end{array}$ & $\begin{array}{c}-0.0135^{* *} \\
(0.0031)\end{array}$ & $\begin{array}{c}-0.0122^{* *} \\
(0.0029)\end{array}$ \\
\hline$s$ & $\begin{array}{c}1.151 \\
(0.783)\end{array}$ & $\begin{array}{c}1.192 \\
(0.862)\end{array}$ & 1 & 1 \\
\hline \# of observations & 84 & 84 & 84 & 84 \\
\hline log likelihood & 274.5 & 273.7 & 274.4 & 273.6 \\
\hline Wald P-value & 0.00 & 0.00 & 0.00 & 0.00 \\
\hline
\end{tabular}

note: Estimation by maximum likelihood with standard errors presented in parentheses. ${ }^{* *}$ denotes statistical significance at the $5 \%$ confidence level while $*$ denotes statistical significane at the $10 \%$ confidence level. 
Table 4

Regression Results: $\log \bar{H}_{1960-1995}$ and Geo-Political Variables

\begin{tabular}{ccccccc}
\hline & Model 1 & Model 2 & Model 3 & Model 4 & Model 5 & Model 6 \\
\hline & & & & & & \\
& -0.0671 & - & $-0.0778^{*}$ & - & $-0.1394^{* *}$ & - \\
$\ln \left(\bar{H}_{1960-1995)}\right)$ & $0.0463)$ & & $(0.0461)$ & & $(0.0488)$ & \\
& 0.0077 & 0.0070 & 0.0072 & $0.0067^{*}$ & 0.0092 & $0.0080^{* *}$ \\
$\ln \left(\bar{H}_{1960-1995)}\right)$ & $-0.0061)$ & $(0.0043)$ & $(0.0054)$ & $(0.0038)$ & $(0.0077)$ & $(0.0038)$ \\
$*\left(\frac{T F P_{i}}{T F P_{m}}\right)^{* *}$ & $-0.0164^{* *}$ & $-0.0194^{* *}$ & $-0.0159^{* *}$ & $-0.0213^{* *}$ & $-0.0142^{* *}$ \\
$s$ & $(0.0066)$ & $(0.0045)$ & $(0.0059)$ & $(0.0041)$ & $(0.0082)$ & $(0.0043)$ \\
& 0.9302 & $1.1380^{*}$ & $0.9866^{*}$ & $1.2250^{*}$ & 0.8375 & 1.2780 \\
ssafrica & $(0.5796)$ & $(0.6534)$ & $(0.5621)$ & $(0.6414)$ & $(0.5857)$ & $(0.7953)$ \\
& -0.0041 & $-0.0049^{*}$ & - & - & -0.0047 & $-0.0065^{* *}$ \\
access & $(0.0030)$ & $(0.0030)$ & & & $(0.0032)$ & $(0.0033)$ \\
& -0.0018 & -0.0027 & -0.0026 & -0.0038 & 0.0002 & -0.0015 \\
tropics & $(0.0027)$ & $(0.0026)$ & $(0.0026)$ & $(0.0026)$ & $(0.0029)$ & $(0.0030)$ \\
& $-0.0070^{* *}$ & $-0.0074^{* *}$ & $-0.0073^{* *}$ & $-0.0078^{* *}$ & $-0.0086^{* *}$ & $-0.0096^{* *}$ \\
life1 & $(0.0026)$ & $(0.0026)$ & $(0.0026)$ & $(0.0026)$ & $(0.0027)$ & $(0.0028)$ \\
& $0.0201^{*}$ & $0.0031^{* *}$ & $0.0228^{*}$ & $0.0031^{* *}$ & $0.0393^{* *}$ & $0.0044^{* *}$ \\
ethling & $(0.0117)$ & $(0.0007)$ & $(0.0117)$ & $(0.0007)$ & $(0.0123)$ & $(0.0008)$ \\
& 0.0001 & 0.0000 & 0.0000 & -0.0000 & $0.0001^{*}$ & 0.0000 \\
openess & $(0.0000)$ & $(0.0000)$ & $(0.0000)$ & $(0.0000)$ & $(0.0000)$ & $(0.0000)$ \\
& $0.0128^{* *}$ & $0.0140^{* *}$ & $0.0128^{* *}$ & $0.0143^{* *}$ & - & - \\
& $(0.0027)$ & $(0.0026)$ & $(0.0027)$ & $(0.0026)$ & & \\
\# of observations & 75 & & & & & \\
log likelihood & 259.8 & 258.7 & 258.8 & 257.4 & 261.2 & 257.3 \\
Wald P-value & 0.00 & 0.00 & 0.00 & 0.00 & 0.00 & 0.00 \\
\hline
\end{tabular}

note: Estimation by maximum likelihood with standard errors presented in parentheses. $* *$ denotes statistical significance at the $5 \%$ confidence level while $*$ denotes statistical significane at the $10 \%$ confidence level. See text for definitions of the conditioning variables. 
Table 5

Point Estimates

\begin{tabular}{ccccc}
\multicolumn{5}{c}{$H_{1960}$} \\
\hline & Model 1 & Model 2 & Model 3 & Model 4 \\
\hline$g$ & -0.0006 & 0.0031 & 0.0012 & 0.0063 \\
$c$ & 0.0198 & 0.0268 & 0.0089 & 0.0072 \\
$s$ & 2.3040 & 3.1645 & 1 & 1 \\
$H_{60}^{*}$ & n.a. & 1.78 & 1.29 & 2.75 \\
$H_{95}^{*}$ & n.a. & 1.95 & 1.35 & 3.22 \\
\hline
\end{tabular}

\begin{tabular}{ccccc}
\multicolumn{5}{c}{$\bar{H}_{1960-1995}$} \\
\hline & Model 1 & Model 2 & Model 3 & Model 4 \\
\hline$g$ & 0.0046 & 0.0034 & 0.0049 & 0.0037 \\
$c$ & 0.0149 & 0.0138 & 0.0135 & 0.0122 \\
$s$ & 1.1515 & 1.1921 & 1 & 1 \\
$H_{60}^{*}$ & 1.76 & 1.63 & 1.78 & 1.65 \\
$H_{95}^{*}$ & 1.93 & 1.76 & 1.95 & 1.79 \\
\hline
\end{tabular}

note: $g, c$, and $s$ are obtained from the point estimates presented in Tables 2 and $3 . H_{60}^{*}$ and $H_{95}^{*}$ represent the minimal initial estimated stock of human capital needed for positive predicted growth relative to the leader nation. 
Table 6

Nations with Slow TFP Growth (1960)

\begin{tabular}{|c|c|c|}
\hline Country & $H_{1960}$ & $\left(\right.$ TFP Growth $\left._{i}\right)-($ TFP Growth $U S A)$ \\
\hline Nepal & 0.07 & -0.0072 \\
\hline Mali & 0.17 & -0.0199 \\
\hline Niger & 0.20 & -0.0297 \\
\hline Mozambique & 0.26 & -0.0307 \\
\hline Togo & 0.32 & -0.0172 \\
\hline Central African Republic & 0.39 & -0.0295 \\
\hline Iran & 0.63 & -0.0050 \\
\hline Pakistan & 0.63 & 0.0063 \\
\hline Ghana & 0.69 & -0.0067 \\
\hline Bangladesh & 0.79 & -0.0084 \\
\hline Algeria & 0.97 & -0.0067 \\
\hline Syria & 0.99 & 0.0034 \\
\hline Uganda & 1.10 & -0.0090 \\
\hline Indonesia & 1.11 & 0.0095 \\
\hline Papua New Guinea & 1.13 & -0.0057 \\
\hline Kenya & 1.20 & -0.0061 \\
\hline Cameroon & 1.37 & -0.0169 \\
\hline Jordan & 1.40 & -0.0082 \\
\hline Guatemala & 1.43 & -0.0067 \\
\hline India & 1.45 & 0.0013 \\
\hline Botswana & 1.46 & 0.0168 \\
\hline Zimbabwe & 1.54 & -0.0002 \\
\hline Senegal & 1.60 & -0.0198 \\
\hline Zambia & 1.60 & -0.0238 \\
\hline Honduras & 1.69 & -0.0122 \\
\hline Malawi & 1.70 & -0.0070 \\
\hline El Salvador & 1.70 & -0.0116 \\
\hline
\end{tabular}

note: The nations listed are those with 1960 human capital levels below 1.78, the minimum needed for TFP catchup according to Model 2 in Table 2. 


\section{Table 7}

\begin{tabular}{ccc} 
Nations with Slow TFP Growth (1995) \\
\hline Country & $H_{1995}$ & $\frac{T F P_{1995 i}}{T F P_{19954}}$ \\
\hline Mali & 0.69 & 0.1188 \\
Niger & 0.69 & 0.1152 \\
Mozambique & 1.01 & 0.1499 \\
Nepal & 1.53 & 0.1489 \\
\hline
\end{tabular}

note: The nations listed are those with 1995 human capital levels below 1.95, the minimum needed for TFP catchup according to Model 2 in Table 2. For the full 84 country sample, $\frac{T F P_{1995 i}}{\frac{T F P 1995 U S A}{S A}}=0.4377$ 
Figure 1

TFP Growth vs Initial Human Capital

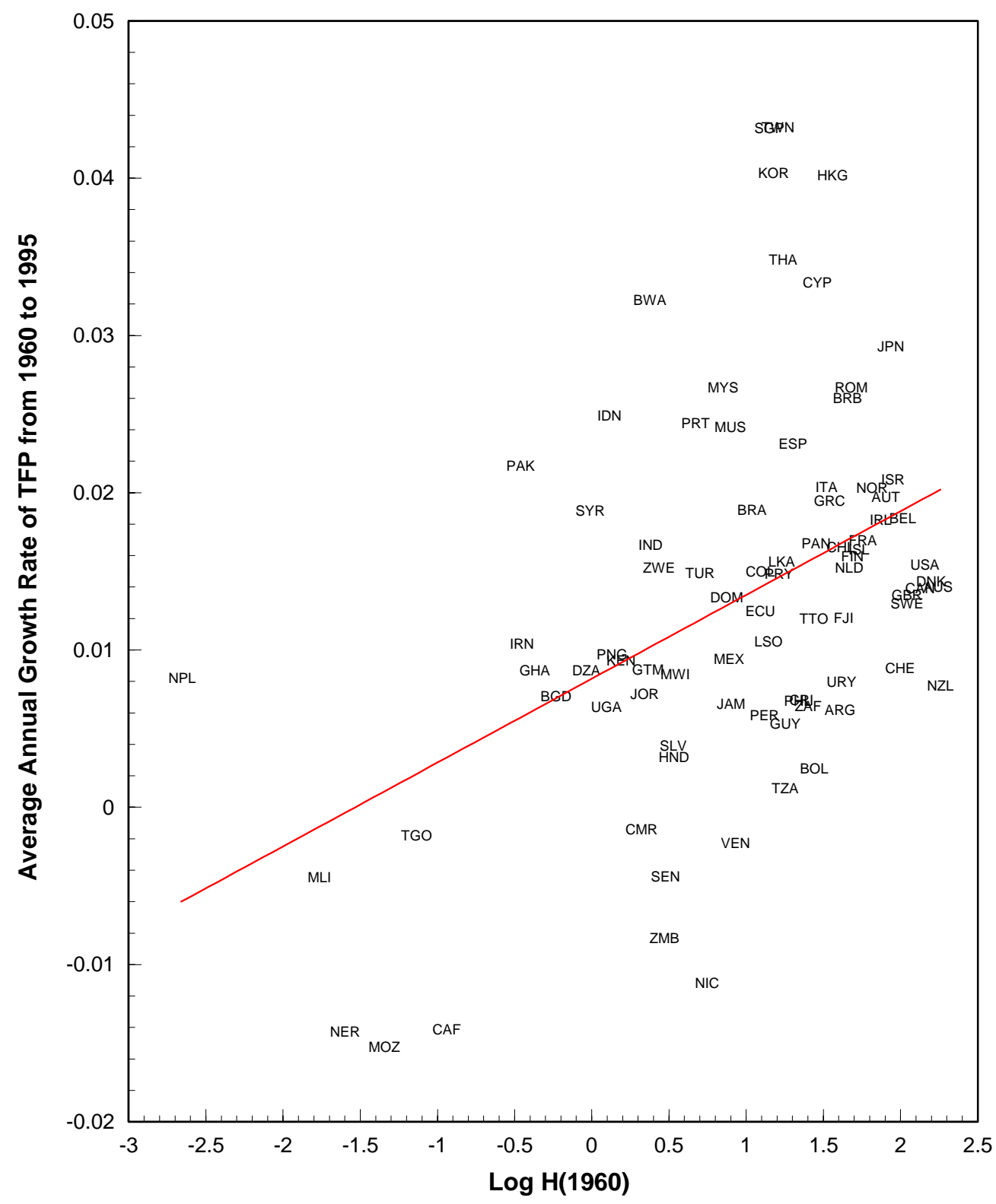


Figure 2

Predicted Values of $B_{i}(1995)^{1}$

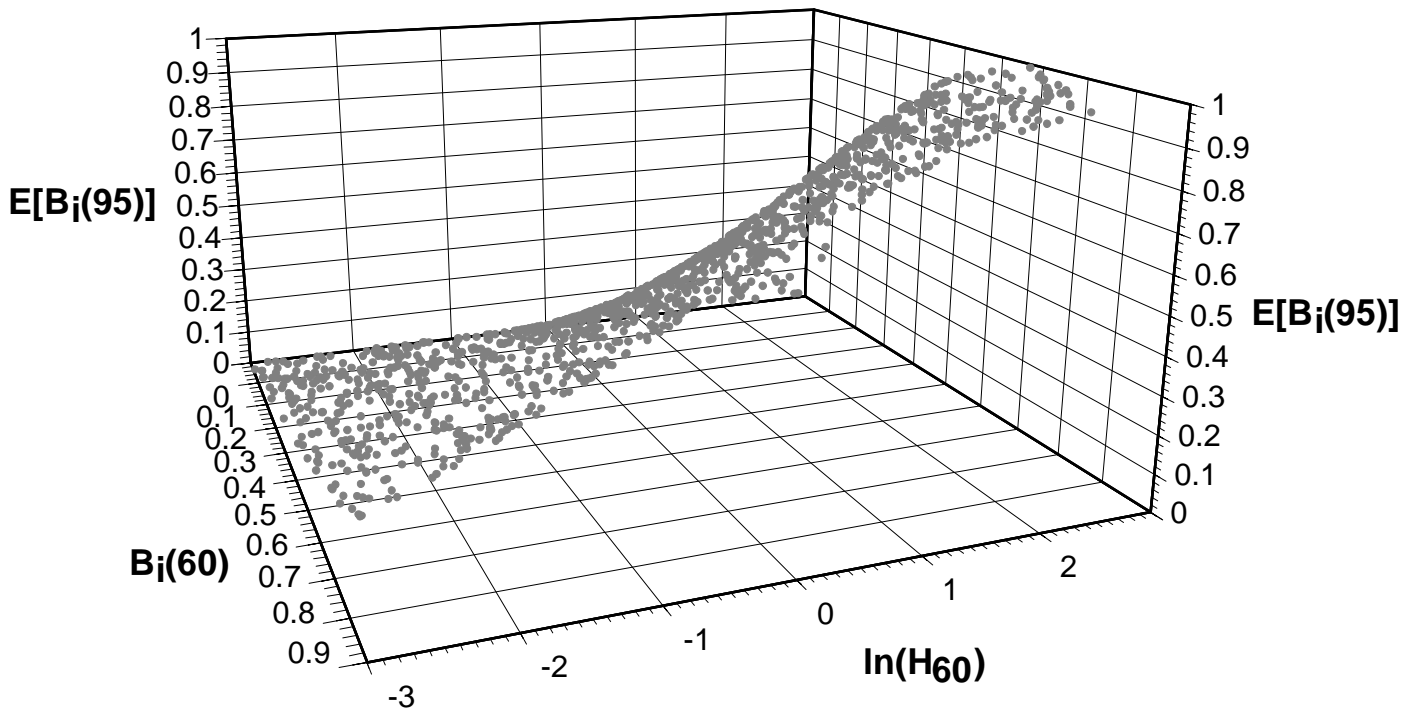

${ }^{1}$ Predicted values of $B_{i}(95)$ are based on initial backwardness in TFP, $B_{i}(60)$, and the log of initial stock of human capital. $B_{i}(t)$ represents the ratio of TFP in country $i$ to TFP in the leader country (United States) at time $t$. The sample encompasses the entire range of values for backwardness and human capital. 
Figure 3

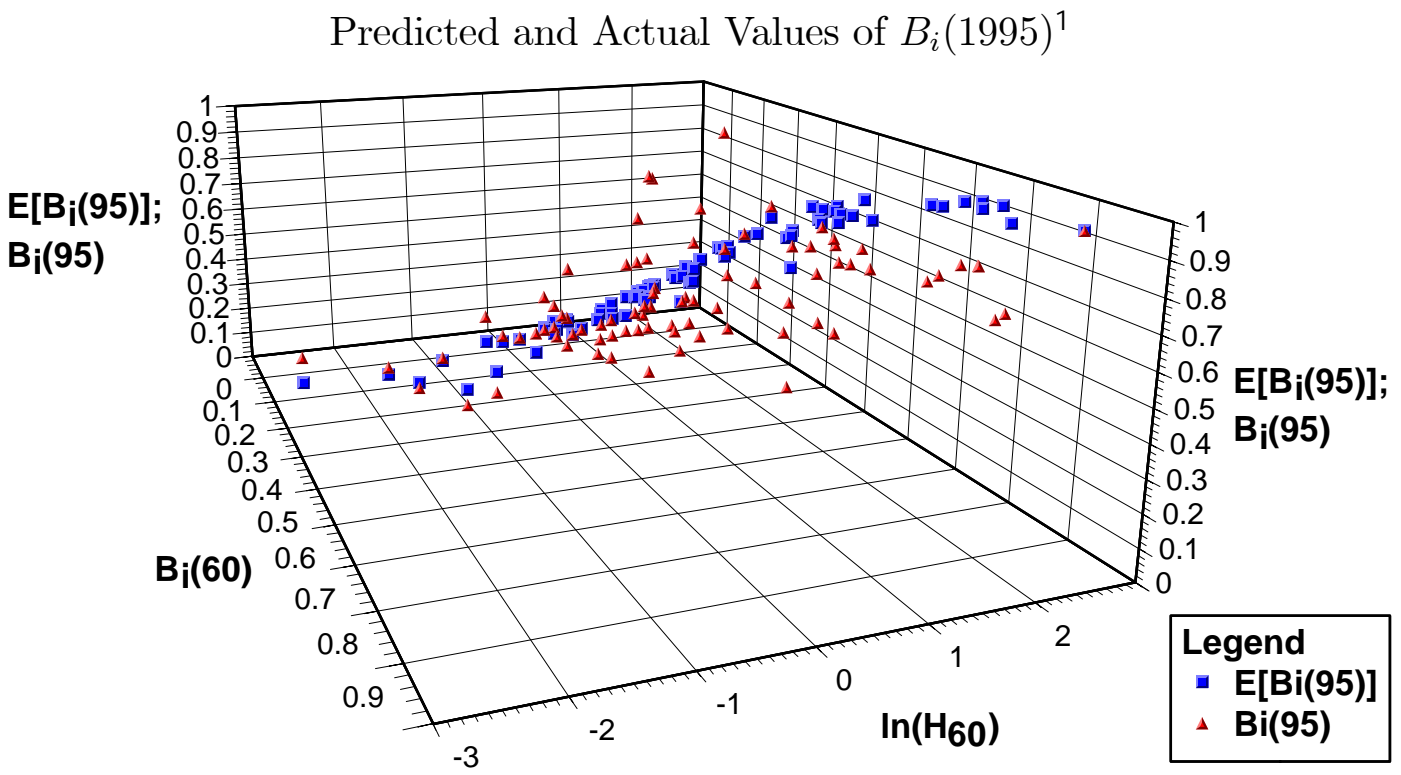

${ }^{1}$ Predicted values of $B_{i}(95)$ are based on initial backwardness in TFP, $B_{i}(60)$, and the log of initial stock of human capital. $B_{i}(t)$ represents the ratio of TFP in country $i$ to TFP in the leader country (United States) at time $t$. The sample includes observed data points only. 